\title{
Optic capture: a management option for intraocular lens tilts in postopen globe injury cataract surgeries
}

\author{
Sudarshan Khokhar, Amber Amar Bhayana ำ, Shreya Nayak, Tavishi Singhal
}

Ophthalmology, Dr Rajendra Prasad Centre for Ophthalmic Sciences, All India Institute of Medical Sciences, New Delhi, Delhi, India

\section{Correspondence to}

Dr Amber Amar Bhayana; amber.amar.bhayana@gmail. com

Accepted 8 April 2021

\section{DESCRIPTION}

A 10-year-old woman with open globe injury sequelae (repaired) and subsequent cataract development was operated for lens aspiration. The cataractous lens had a posterior capsular defect. So after lens aspiration, limited anterior vitrectomy was done and a three-piece intraocular lens (IOL, power 24 dioptre (D)) was placed in the sulcus and optic capture behind the capsule was attempted (figure 1A,B). The patient had an inferior fibrotic hammock of corneocapsular scar, which prevented inferior optic capture and thus postoperatively there was an IOL tilt (inferior optic was relatively anteriorly placed) (figure $1 \mathrm{C}, \mathrm{D})$. The resultant postoperative refraction had a $13 \mathrm{D}$ astigmatism on retinoscopy (the corneal astigmatism on autorefractor-keratometer was only 2 D), indicating the majority astigmatism to be due to lenticular tilt. An IOL repositioning was done in which localised cutting of the inferior fibrotic hammock was done and the optic was captured behind the capsule completely (figure 1E,F). The astigmatism on retinoscopy reduced to $3 \mathrm{D}$. An I-Trace (ray tracing aberrometry) was done after the first surgery and then repeated after IOL repositioning (figure $2 \mathrm{~A}, \mathrm{~B}$ ). The Tracey refraction reduced from $-12.62 \mathrm{D}$ sphere $+9.25 \mathrm{D}$ cylinder at $106^{\circ}$ to $-2.12 \mathrm{D}$ sphere

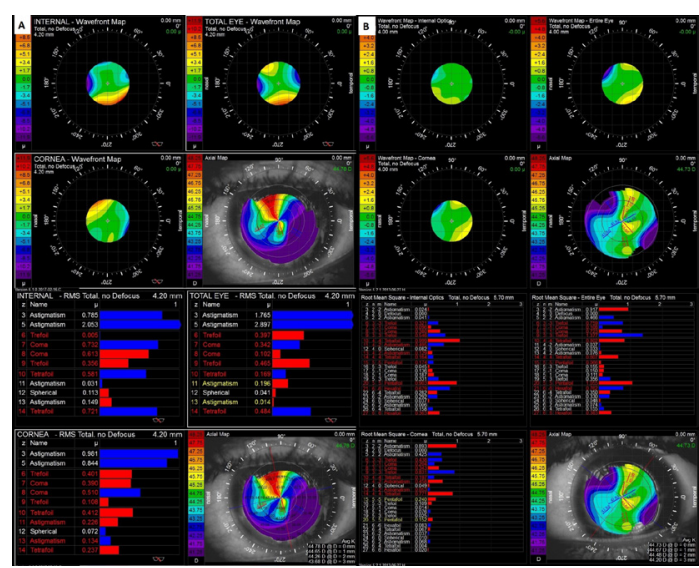

Figure 1 (A) slit lamp photograph after lens aspiration and IOL implantation, (B) retro-illumination showing a centred but tilted IOL in sulcus with $(C)$ inferior IOL optic anterior to capsule resting on the fibrotic hammock (marked by arrow), (D) anterior segment optical coherence tomography showing anterior displacement of inferior optic (marked by arrow), (E) slit lamp photograph after IOL repositioning showing optic well captured behind the capsule, $(F)$ retroillumination photograph of the same. IOL, intraocular lens.
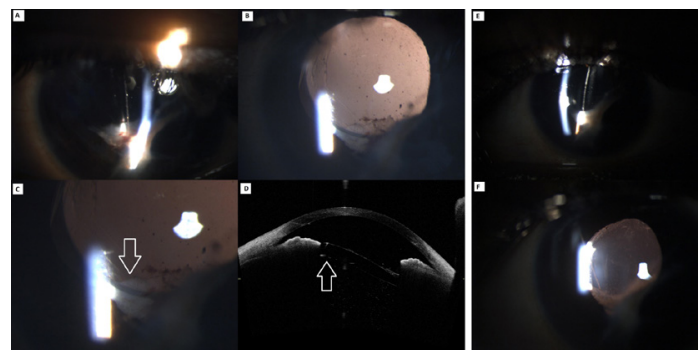

Figure 2 I-Trace imaging of (A) pre-IOL repositioning, (B) post-IOL repositioning. (B) shows considerabely less lower and higher order aberrations as compared with (A). $\mathrm{IOL}$, intraocular lens.

$-1.12 \mathrm{D}$ cylinder at $162^{\circ}$ (table $1-\mathrm{DS}=$ dioptres sphere, $\mathrm{DC}=$ dioptres cylinder).

Tilted IOL has been well documented to manifest as astigmatism. ${ }^{1-3}$ The IOL tilt in our case was measured using an online protractor and the scan with the highest amount of tilt has been displayed and was found to be $14^{\circ}$ anteriorly (figure 3 ). The tilt attributed to $8.13 \mathrm{D}$ of lenticular astigmatism and 5.315 D of myopic shift (difference of spherical equivalents of pre and post-IOL repositioning Tracey refraction). The tilting in our case is different from previous documented cases in that in the earlier documented cases the nasal anterior tilt had an equal amount of temporal posterior tilt (tilt was around the central diameter axis), leaving the centre of mass position of the IOL unaltered. ${ }^{1-3}$ In contrast in our case, the superior optic was well in place, only the inferior optic was anteriorly dislocated (figure 3), resulting in anterior displacement of centre of mass of the lens by half the amount, the cause of the myopic shift. ${ }^{4}$ Traumatic cataracts (open globe injury sequelae) are unique locks each with their own unique keys to surgical approach. Corneoiridic scars, lens rupture and capsular fibrotic involvement make IOL implantation a challenge in these cases due to difficulty in finding a straight plane for IOL implantation. In traumatic cases, irregularity of pupil is another major issue, which makes visibility problematic and may cause visual illusions regarding centration of IOL. The IOL in our case seemed centred intraoperatively, as we could not ascertain any tilt. On first postoperative day, slit lamp examination showed tilting (elicited by oblique slit of light on the IOL). Retinoscopy also showed significant astigmatism re-enforcing our finding. Fluctuation of anterior chamber depth intraoperative or in the immediate postoperative period may cause the IOL to change its position (which might also have been a contributing factor 


\begin{tabular}{lll}
\hline Table 1 & & \\
\hline Parameter & Pre-repositioning of IOL & Post-repositioning of IOL \\
\hline $\begin{array}{l}\text { Retinoscopy } \\
\text { astigmatism }\end{array}$ & 13 D & $3 \mathrm{D}$ \\
\hline Tracey refraction & -12.62 DS/+9.25 DC@ 106 & -2.12 DS/ -1.12 DC@ $162^{0}$ \\
\hline
\end{tabular}

in our case). So, a well-formed anterior chamber with fluid-tight incision is a must, incision to be sutured if necessary. A minor IOL tilt can cause significant ocular morbidity due to lower and higher order aberrations. ${ }^{3}$ I-trace is an objective method of documenting these aberrations and localising the cause of aberrations to cornea or the lens. In the above case, I-trace was not a diagnostic but a reinforcing tool for the findings. In the current era of premium IOLs, where sometimes the patients may not be happy despite an apparently well centred IOL, ray tracing aberrometry comes to a diagnostic rescue.

Optic capture pushes the IOL optic behind the world of tilted sulcus or lenticular bag planes making them a good option in these cases. To confirm an adequate capture, the membrane/

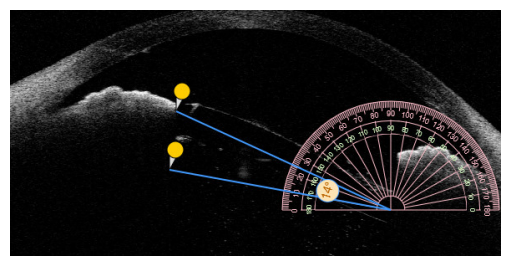

Figure 3 An online protractor superimposed on anterior segment optical coherence tomography image showing anterior tilting of $14^{\circ}$ of inferior optic from the desired IOL plane. IOL, intraocular lens. capsule (behind which the optic is captured) can be nudged with a sinskey blunt hook or viscoelastic cannula just before hydrating the side incision and closing the surgery.

\section{Learning points}

- Intraocular lens (IOL) tilt causes lenticular astigmatism.

- Traumatic cataracts and their outcomes are less predictable than usual cataracts because of variable involvement of cornea, iris, pupil, lens and variable fibrotic changes.

- IOL capture is helpful in such cases as it bypasses the above planes for resting the optic.

Contributors SK-concept, surgery. AAB-surgery, preparation of manuscript. $\mathrm{SN}$ - capturing of data, retrieval of data. TS— retrieval of data.

Funding The authors have not declared a specific grant for this research from any funding agency in the public, commercial or not-for-profit sectors.

Competing interests None declared.

Patient consent for publication Parental/guardian consent obtained.

Provenance and peer review Not commissioned; externally peer reviewed.

\section{ORCID iD}

Amber Amar Bhayana http://orcid.org/0000-0002-0770-601X

\section{REFERENCES}

1 Weikert MP, Golla A, Wang L. Astigmatism induced by intraocular lens tilt evaluated via ray tracing. J Cataract Refract Surg 2018;44:745-9.

2 Kumar DA, Agarwal A, Prakash G, et al. Evaluation of intraocular lens tilt with anterior segment optical coherence tomography. Am J Ophthalmol 2011;151:406-12.

3 Baumeister M, Bühren J, Kohnen T. Tilt and decentration of spherical and aspheric intraocular lenses: effect on higher-order aberrations. J Cataract Refract Surg 2009;35:1006-12.

4 Gatzioufas Z, Kopsidas K, Gyongyossy B, et al. Late-Onset anterior dislocation of a posterior chamber intraocular lens in a patient with pseudoexfoliation syndrome. Case Rep Ophthalmol 2011;2:1-4.

Copyright 2021 BMJ Publishing Group. All rights reserved. For permission to reuse any of this content visit

https://www.bmj.com/company/products-services/rights-and-licensing/permissions/

BMJ Case Report Fellows may re-use this article for personal use and teaching without any further permission.

Become a Fellow of BMJ Case Reports today and you can:

- Submit as many cases as you like

- Enjoy fast sympathetic peer review and rapid publication of accepted articles

- Access all the published articles

Re-use any of the published material for personal use and teaching without further permission

Customer Service

If you have any further queries about your subscription, please contact our customer services team on +44 (0) 2071111105 or via email at support@bmj.com.

Visit casereports.bmj.com for more articles like this and to become a Fellow 